\title{
Western African Student Migration: A Response to the Globalisation of Knowledge
}

\author{
Denise Efionayi and Etienne Piguet
}

\begin{abstract}
While European countries have devoted considerable resources to efforts to block the flow of irregular migration, they have at the same time been vying with one another to attract the best minds and solve the problem of demographic ageing. How do African students navigate through such contradictory policies? This chapter discusses the plans for international migration as expressed by university students from three West African countries (Senegal, Côte d'Ivoire, and Niger). Based in particular on a questionnaire distributed to around 4,000 students, the study identifies a series of factors contributing to students' intention to migrate: family networks abroad, level of educational attainment, lack of confidence in their country's future, supportive attitude of family members, etc. Contrary to the widespread assumptions expressed in the media and in policy debates in industrialised countries, 'migration intentions' appear to be carefully pondered and proactive in nature, rather than impulsive headlong rushes. Students are relatively well informed, and their intentions to undertake what is mostly temporary migration are based on a weighing of their interests in terms of education and professional experience. This article therefore calls for improved coordination of mobility and development policies to unlock the potential of migration while satisfying the thirst for knowledge identified in the three countries concerned.
\end{abstract}

Introduction

Images of shipwrecked migrants off the small Italian island of Lampedusa were broadcast all over the world in October 2013. Apart from their direct emotional impact, these images also reinforced the prevailing narrative maintained by the media and politicians: that of an African continent mired in poverty, instability, and armed conflict. This narrative, reflected in the comments of observers who were both fascinated and horrified by the unfolding drama,

(C) Graduate Institute of International and Development Studies, 2014 | DOI 10.1163/9789004281158_010 This is an open access chapter distributed under the terms of the Creative Commons Attribution- 
has become deeply ingrained in the minds of Europeans. From the perspective of those living north of the Mediterranean, these migrants must be utterly desperate to embark on such a perilous journey, which only a few daring reporters are willing to share.

While more and more resources are being directed towards curbing apparently poverty-driven migration, European countries are vying with one another for the best brains to tackle the problems of an ageing population and the future needs of a globalised labour market. This strategy includes, or even hinges upon, attracting the world's best researchers to the European Higher Education Area. However, it largely disregards Africa, despite close geographic and economic ties, and the continent's young population, markedly increasing school attendance rates, and similar education systems, which are largely modelled on those of former colonial powers. The European Union's mobility partnerships - or 'migration partnerships' as they are referred to in Switzerland-are more concerned with matters of return and cooperation in the countries of the South than they are with developing educational or employment prospects for young people from 'partner countries'. When decision-makers mention shortages of qualified workers in IT, engineering, or even health care, their gaze usually turns to Asia or North America as potential sources of skilled workers.

Grants and other programmes facilitating mobility in globalised higher education are mostly directed at the major emerging economies, which present significant economic growth prospects. African student mobility, in contrast, is mostly associated with poverty-driven migration. Student migration to former colonial countries, and later to North America, has nevertheless been commonplace ever since African nations gained their independence. Many of the parents and teachers of today's African students were educated in Britain, France, Germany, or Switzerland. The available data from some African countries show that university students are more likely to emigrate on a temporary basis than their less well-educated compatriots. Even prior to the introduction of the Bologna process in Europe, and subsequently in Africa, international mobility ratios ${ }^{1}$ for African students were among the highest in the world. And yet, this group remains one of the least studied categories of migrants (Piguet, 2013b).

Given the above, it would be interesting to know how young university students from sub-Saharan Africa feel about mobility issues and how they view their futures in terms of education and employment. These questions are at the

1 International mobility ratio: the number of students enrolled abroad compared with those studying at higher education institutions in their own countries. 
heart of a study conducted among several thousand students in West Africa on behalf of the Swiss Network for International Studies (SNIS). The main aim of the study was to understand how the migration option - whether temporary or long-term - forms part of the life plan of individuals and families and how those wishing to emigrate differ from those who do not intend to leave their own countries. In order to achieve this objective, the following research questions were addressed:

- Which socio-demographic, economic, biographical, and geographical factors play a role in students' aspirations to migrate? What factors discourage mobility?

- What is the geographical distribution of the destinations considered? What reasoning can be derived from this geographical distribution?

- More generally, what lessons may be retained for development, education, and migration policies in both the South and the North?

The question of why people choose to migrate and how they migrate has been of concern to social scientists for over a century. The determinant factors include geography, psychology, economics, sociology, anthropology, and demographics. As Babacar Ndione explains (2007, 326),

It is now acknowledged that a prospective migrant's willingness and ability to migrate abroad depend on their personality and socioeconomic trajectory, their domestic and community environment, the flows of information to which they are exposed, migration networks and the political and economic context of the receiving country.

In the present study, we focus on the initial stages of migration, namely the forming of an intention to migrate and the initial steps that follow. Our hypotheses are based on a pluralist model that aggregates migration flows at the macro level and considers decision-making theories centred on the immediate surroundings and motivations of individuals (Piguet, 2013a).

Our system of hypotheses was partly inspired by the work of Gordon De Jong (2000), who analysed the determinant factors of decisions for or against migration, as well as the factors allowing migration to take place. De Jong highlighted five significant factors that came out of the literature: (1) transnational networks, (2) values and concrete expectations of migration, (3) family norms, (4) gender roles, and (5) satisfaction with living conditions. Also taken into account were direct opportunities and constraints, which are viewed as facilitating or discouraging factors rather than catalysts per se: financial means, 
prior experience of migration, professional contacts, etc. In order to complete and adapt this list to the specific situation of students, we have identified the following groups of determinant factors, which combine three analytical dimensions relating to students' individual situations, social dynamics (e.g. the role of families), and the political and sociocultural contexts of the countries concerned: ${ }^{2}$

1. Educational context (discipline studied, level of attainment, satisfaction, etc.).

2. Social, demographic, and psychological factors (gender, age, childhood home).

3. Family context (civil status, siblings, family background).

4. Transnational networks and connections (friends and family abroad, experience of migration).

5. Social and cultural context (country, religion, ethnic group).

6. Political context (perception of institutions, gender equality).

7. Economic and material factors (resources, confidence in economic prospects).

8. Quality of life (housing, environment, health-care system).

It goes without saying that these dimensions must be considered as interacting with one another, rather than being mutually exclusive.

This study is mainly interested in students' intentions, aspirations, and motivations in their decisions on whether to stay or go. It also takes into account the preliminary steps taken towards the implementation of migration plans, such as information gathering. It has not sought to establish, however, whether the person actually migrated at a later time. Here, the intention to migrate is considered separately from the act of doing so, which depends on specific opportunities to put plans into action and, especially in the case of young students, on the family's decision to support an individual's plans. However, several research studies show, as far as migration is concerned, that people's intentions and actions are frequently linked and respond to similar explanatory factors (Lu, 1999; Dalen et al., 2005).

2 The latter aspect has been investigated in national studies, although space constraints have made it impossible to discuss it in this article. Cf. Leave or stay? Migration in the life plans of students in West Africa (2011): Report on Côte d'vvoire by Raffaele Poli and Désiré Nassa; Report on Niger by Patrick Gilliard and Amadou Oumarou; Report on Senegal by Jérôme Chenal and Yves Pedrazzini, http://www.migration-population.ch/sfm/publications (accessed on 19 May 2014). 
The research plan was based on both a quantitative and qualitative approach to students from three West African universities, in Côte d'Ivoire (Abidjan), Niger (Niamey), and Senegal (Saint-Louis). These three contexts, despite differences between the countries, have many points in common. The research consisted of three successive empirical stages:

- A series of exploratory, semi-structured interviews with students and specialists in the three cities. This enabled an almost identical semistandardised questionnaire to be developed for all three case studies.

- A questionnaire survey among more than 4,000 students. Respondents were selected on a random basis from various faculties on the three campuses.

- Around 50 semi-structured follow-up interviews with students to elaborate on specific survey results.

The exploratory interviews were thematic (attitudes to migration, local opportunities and alternatives, knowledge of various destinations, etc.), methodological (expected progression of survey), and organisational (local partners, authorisations, selection of locations, etc.). These questions were discussed with 18 experts-researchers, university staff, and representatives of the relevant authorities, NGOs, and international organisations-and with 29 students. Conducted by Swiss and/or local staff from October to December 2008, these interviews also shed light on the situation of each university and on the numbers of people who were studying there or who had emigrated, as well as on the characteristics of students. A series of exchange workshops and on-site work assignments allowed a common approach to be developed while taking specific local factors into account.

The quantitative data were gathered between 20 April and 15 May 2009, in direct collaboration between the project managers at the universities of Neuchâtel and Lausanne (Switzerland) and the research teams at the three West African universities. Despite a number of setbacks including a strike at Gaston Berger University, Saint-Louis, all the surveys were carried out in favourable conditions and drew considerable interest from respondents. This undoubtedly helped to increase the reliability of responses. There were relatively few refusals to participate- the response rate was 90 per cent in Niger and Senegal, and 47 per cent in Côte d'Ivoire. ${ }^{3}$ Generally speaking, the profile

3 This difference may be explained by campus configurations. In Côte d'Ivoire, due to the size of the university, questionnaires were distributed at the front entrance of the campus, where there was a large flow of students. Many students chose not to respond due to a lack of time. 
of students who responded to the questionnaire matched that of the student population as a whole in terms of age, gender, and faculties or branches of study, etc. ${ }^{4}$ In Saint-Louis, a small minority of students expressed concern regarding the anonymity of the results, but the follow-up interviews and discussions with students show that, on the whole, they had responded sincerely and the results were highly reliable.

The results were taken from a total of 4,106 valid questionnaires. ${ }^{5}$ In order to gauge the individual impact of the various explanatory factors identified in our system of hypotheses, we used logistic regressions to explain a binary variable, 'migration intention', which is defined below. This is a multivariate analysis because it simultaneously considers all potential explanatory variables. For example, it allows us to determine, ceteris paribus (i.e. same gender, same age, etc.), whether people who judge their financial means to be insufficient express a stronger intention to leave their country. It also allows us to determine the extent to which financial considerations play a role in shaping migration intention. ${ }^{6}$

Once questionnaire responses had been fully analysed, a total of 47 followup interviews were held with students of various disciplines to discuss the results. Conducted between February and July 2010, this third stage of the study allowed the quantitative results to be elaborated further and helped to clarify uncertainties. Although carried out slightly differently in each context,

In Senegal, where questionnaires were distributed at on-campus dormitories and where respondents were given the option of returning the questionnaire to interviewers on the following day, most students agreed to respond.

4 Just over a quarter of the respondents were female. While this matches the proportion of enrolments in Niger, female students were overrepresented among respondents in Senegal (38 per cent) and slightly underrepresented in Côte d'Ivoire. At each university, the distribution of studies represented by respondents was relatively close to the actual distribution of studies for the student body as a whole, reflecting a very wide range of disciplines-leaving medicine aside as it is only taught in Niamey. Most students held upper-secondary level qualifications (38 per cent) or a Bachelor's degree (52 per cent); only 10 per cent had a Master's degree. More Senegalese students (20 per cent) had already attained a Master's degree. Although the sample was widely representative of the student body, it seemed to contain a bias towards those in the early stages of their studies, which may be explained by their greater availability or presence on campus when the questionnaire was being distributed.

5 The largest sample, with 1,757 questionnaires, was from the biggest of the universities, the Université Félix Houphouët-Boigny in Abidjan. This was followed by the sample from the Abdou Moumouni University in Niamey (1,501 questionnaires), and the sample from the Gaston Berger University of Saint-Louis (848 questionnaires).

6 The coefficients for the different models used were explained in detail in the working paper that followed the study (Piguet, 2013b, 19-20). 
the interviews mainly focussed on interpreting and verifying the available data with the help of students who were already far advanced in their studies in various disciplines and who were familiar with the situation at the university.

In the following paragraphs, we will briefly set out the contexts of the universities in the three countries studied (2). We will then cover the indicators used to analyse migration intentions and the main relevant results (3). The various explanatory factors behind these intentions and the choice of destinations will be discussed after this (4) before giving an assessment of the policy implications of our findings (5).

\section{University Contexts}

Although this research consists of three case studies, the aim is not to compare the countries concerned to each other. Most of the analysis relating to individual decision-making processes and attitudes towards migration apply to all those interviewed. However, specific features of the university settings in the three countries should be noted to better understand the situations and university careers of the students.

With around 54,000 students, the Université Félix Houphouët-Boigny (formerly the University of Cocody-Abidjan) is by far the largest of the three universities. Its student numbers have steadily increased, which presents challenges in terms of infrastructure and quality of teaching. Many students perceive it to be the 'university for the poor', since there are several private universities in Côte d'Ivoire that attract students who are able to pay their high registration fees. Foreigners and inhabitants of the north of the country are underrepresented in the student body for both political and economic reasons. It should also be noted that the deterioration in the political and economic situation in Côte d'Ivoire from 2002 onwards had repercussions in the university sector. University dormitories are full, which obliges many students to live in other parts of Abidjan. Only a small minority of those who enrol receive a state grant and when the survey was conducted fewer than half the students interviewed (44 per cent) said they were satisfied with the quality of teaching (compared with around 66 per cent in Niger and Senegal).

In Niger, few disciplines are taught in private universities, and Abdou Moumouni University in Niamey is the only public university in the country. It has 10,000 students, and enjoys a good reputation. Around a quarter of these students receive grants. Like in Abidjan, university accommodation is completely full, which forces some students to live on the outskirts of Niamey. Ranked as the world's poorest country in the Human Development Index of 
the United Nations Development Programme (UNDP), Niger has the lowest higher education attendance rates for the continent after Malawi (Findlay et al., 2012; Mounkaila et al., 2009). Unlike at the two other universities considered in this study, it is not possible to obtain a $\mathrm{PhD}$ or doctorate in Niger for most disciplines; students are therefore forced to go abroad to complete their education (Tabapssi, 2010).

With its 5,000 students, Gaston Berger University, Saint-Louis, Senegal, is considered one of the best in the country. Senegal has long played a pioneering role in establishing higher education in French-speaking sub-Saharan Africa. It also has several private universities, but Gaston Berger University holds second place after Dakar's Cheikh Anta Diop University in several international ranking lists. Since it was founded in 1990, Gaston Berger has operated a selective quota system, limiting entry to the best students in the country, many of whom benefit from a state grant (Goudiaby, 2009).

Student assessments of their own financial means tally with the economic situation of their respective universities and, more generally, their countries of residence. These indicators are less favourable for students from Côte d'Ivoire compared with those from Niger and even worse compared with those from Senegal. ${ }^{7}$ The crisis that struck Côte d'Ivoire in 2009 should be borne in mind in this regard. Despite local conditions, the economic situation of students should not be conflated with that of other groups within the population. In the three countries studied, university students tend to be from a relatively privileged fringe of society, often from families within the political, economic, or intellectual elite of the middle classes.

Most students have a relatively damning opinion of study conditions in terms of resources (computers, textbooks, rooms, etc.) and, to some extent, the quality of teaching. These assessments are hardly surprising given the deterioration in the university situation as documented by specialists in the field (Khelfaoui, 2009), who also highlight significant political interference in academic affairs. This interference was bemoaned in comments from several students, many of whom, particularly in Côte d'Ivoire, have had whole years written off ('blank years') because of strikes or political developments.

Even if opinions differ between campuses, with students from Niger tending to be less critical, one is left with an image of general dissatisfaction with study conditions. To what extent can this be linked to the migration intentions of individuals? Do other factors come into play? It is precisely these questions that lie at the heart of our research.

7 Means at one's disposal (average), perception, and development of financial situation over previous five years. 
When asked whether they would like to live abroad in the relatively near future either to work, to study, or for any other reason, around 38 per cent of students responded fairly categorically in the negative, although practically the same proportion of them had a 'strong desire' or 'very strong desire' to live in another country (Figure 9.1). In total, over 60 per cent of students were considering spending some time abroad. Unfortunately, we do not have comparable data for other student populations of a similar average age (24.5). For indicative purposes, one could cite the Eurobarometer survey that estimates that a little over half of Europeans aged between 15 and 35 are prepared to consider working in another European country (European Commission, 2011).

The vast majority of students who wanted to leave (83 per cent) also said that they had a specific migration plan in mind. However, since respondents tended to be in the early stages of their degree programmes, most (52 per cent) intended to migrate after they had obtained their next qualification or once their studies were complete. A non-negligible proportion (40 per cent) remained uncertain regarding the best time to leave. The varying stages of preparation no doubt account for the fact that only 27 per cent of respondents had already taken specific steps to implement a migration plan, even if it was

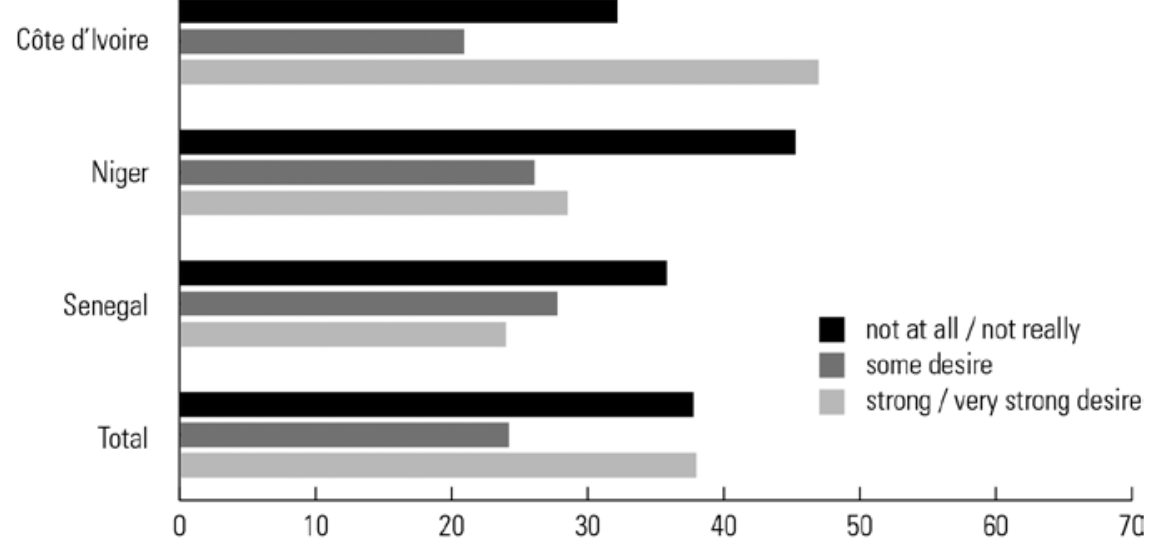

FIGURE 9.1 Desire among students to live abroad, by country.

Note: Students responded to the following question-'If you had the chance, would you want to live abroad in the relatively near future?' SOURCE: AUTHORS. 
only to consult the Internet ${ }^{8}$ or to seek information from an embassy. When such measures prove unsuccessful, they can result in a student abandoning the idea of leaving: 23 per cent of respondents who had already taken such a step no longer wished, at the time of the survey, to live abroad. As other researchers have pointed out (Armitage and Conner, 2001; Lu, 1999; van Dalen et al., 2005), there are multiple interdependencies between wanting to leave, having a specific plan, and actually implementing it. The personal interviews showed that a concrete migration plan is sometimes more of a reaction to the decisions of the people around students than the result of students' own desire to leave. The abandonment of such plans despite having already taken some steps may also be a response to administrative barriers, or it could reflect the dispelling of certain misconceptions.

In order to identify the determinant factors behind a relatively strong desire to migrate, a cumulative indicator comprised of three criteria was used: expressed desire to leave, the existence of a precise plan, and at least one step already taken towards implementation. ${ }^{9}$ On this basis, the proportion of students declaring an intention to migrate falls to 17 per cent of respondents as a whole, albeit with marked differences between the three countries. The figure for Senegalese students is twice as high (32 per cent) as that of Côte d'Ivoire (16 per cent) and three times higher than that of Niger (11 per cent). The differences are accentuated even further in terms of concrete steps taken, these being more common in Senegal. At Gaston Berger University, competitions are arranged to award mobility scholarships to the best baccalaureate pupils as well as to students enrolled in the second and third cycle of university studies. ${ }^{10}$ Magatte Fall (2010) described 'the recruitment of whole squads of successful candidates thanks to a system of grants for specialisation in specific fields'.

8 An information search of this sort might at first appear trivial, but the interviews put this into perspective: making the effort to carry out such a search already implies an intention to leave. First, students do not necessarily know how to get the information or what site to consult; second, reliable Internet access is far from guaranteed for all.

9 The decision to simplify the analysis by considering a binary choice was reinforced by results obtained from alternative models using either other binary re-coding or ordered multivariate variables (multinomial logistic regression). The gain in goodness of fit turned out to be negative or marginal, and the list of significantly correlated independent variables was shown to be relatively stable between models.

10 This opportunity to study abroad exists thanks to agreements signed within the framework of dynamic partnerships with organisations in countries such as France, the United States, Canada, and Japan. 
Whereas, on the whole, there is only a marginal distinction between men and women in terms of their desire and firm intention to migrate, gender differences are of central importance in some contexts. A much higher proportion of Senegalese women intended to emigrate compared with their male compatriots (42 per cent as opposed to 27 per cent). The reverse was the case in Côte d'Ivoire (11 per cent compared with 17 per cent). In principle, patriarchal structures tend to encourage male emigration, although it is possible that the symbolic value of emigrating might prove more 'profitable' for womenand their families-by allowing them to overcome the specific difficulties that they encounter in the labour market. It emerged from the interviews that female students in Senegal were highly confident about their chances of securing high-level jobs following a period abroad. A number of examples of women securing managerial positions within public administration may have had a ripple effect. Other research suggests that female students tend to come from more privileged social backgrounds (Biraimah, 1987; Kunzler, 2008; Lebeau, 1997). For the upper-middle class, studying abroad could be a springboard and a way of overcoming certain barriers to women's social mobility in their countries of origin, barriers which the wealthiest people in society do not face.

A further element of the gender dimension arises from the fact that female students are more careful about ensuring that their university career does not come at the expense of family life. During personal interviews, several female respondents stressed that long courses of study were likely to reduce their chances of getting married. Beyond a certain age, being single is not an option that is freely tolerated in societies that favour family traditions. While the degree of importance accorded to family life over individual aspirations varies in the three countries considered, family life takes precedence in all cases.

The influence of family considerations in forming the intention to migrate has been confirmed by a series of other results. The desire to leave tends to diminish with age and following marriage, especially for women. The attitude of one's partner - or indeed, the impossibility of migrating as a couple or a family (Geddie, 2013) — seems to play a crucial role. More generally, multivariate analysis emphasises the decisive influence that family support exerts, in a broad sense, on the intention to leave. Whereas, in all countries, the family's support for emigration is marked (Figure 9.2), students who lack such support are far less likely to make concrete plans to leave. Along with networks of contacts abroad, family support is one of the most important factors determining the decisions to leave or stay for both men and women at the three universities. 


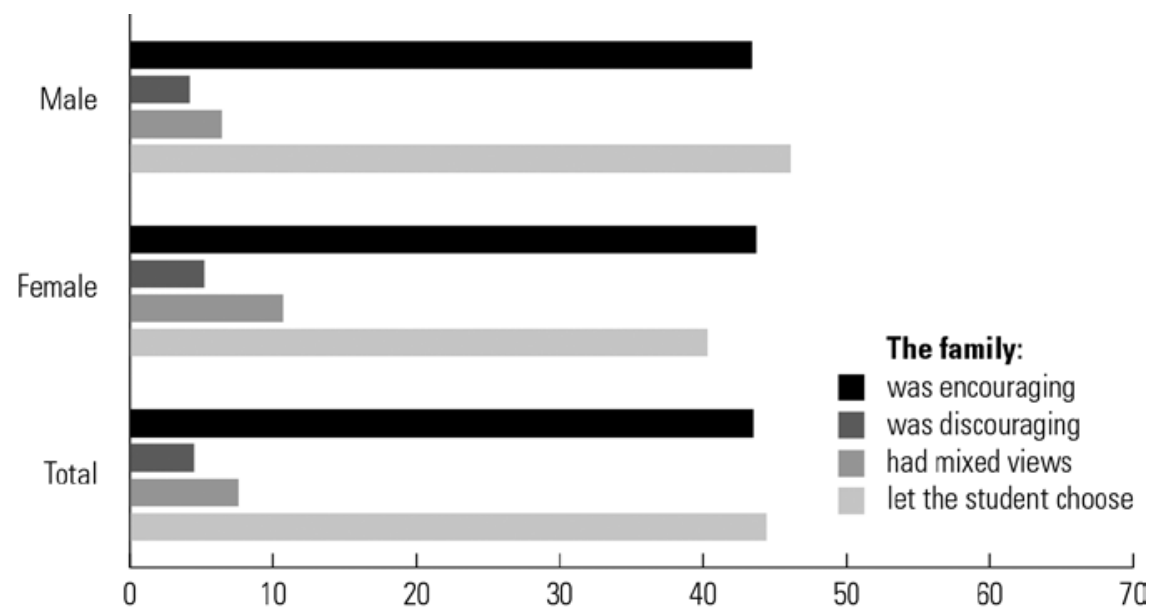

FIGURE 9.2 Attitude of family to departure of student, by student's gender.

Note: Students answered the following question-'Has your family encouraged or urged you to live or study abroad?' Those respondents who had not raised the matter with their families (30 per cent) were not included. SOURCE: AUTHORS.

The importance of the family's role in the various types of migration and its impact at different stages of the migration process have been confirmed by many empirical and theoretical studies (De Jong, 2000; Harbinson, 1981; Palloni et al., 2001), including those in the new economics of migration (NEM) field. Among those students who had spoken with their families about the possibility of living abroad, 44 per cent were encouraged to do so, and a similar number reported that their family had left them free to choose. Only a small minority ( 5 per cent) had been dissuaded. However, Nigerien families, and in general the families of female students in all three countries, were more likely to have mixed views. This favourable inclination towards mobility is reinforced by the social prestige that university study abroad brings not only to the students themselves, but to their extended families as mentioned in qualitative interviews. Whereas the symbolic distinction of this sort of international experience is not unique to the African context, it is particularly significant with regard to upward social mobility in developing countries (Pinto, 2013).

Despite the numerous arguments in favour of migration, there is a fringe group comprising around one-fifth of the students interviewed who said that they were resolutely opposed to going abroad, with neither the inclination nor any plans to go away-and who had not taken any steps in this regard. Multivariate analysis shows that the likelihood of falling into this 
group increases if one is: a woman, older, has children, has confidence in the future of the country, and is satisfied with the resources available at the home university. A discouraging attitude on the part of family members is also influential in this regard.

These initial results allow us to construct a general outline of the factors that contribute to the migration intentions of students (Figure 9.3). They also reveal the coherent, considered nature of attitudes to migration and how they are affected by the level of satisfaction with the university and political climate. We will revisit these themes in the next section.

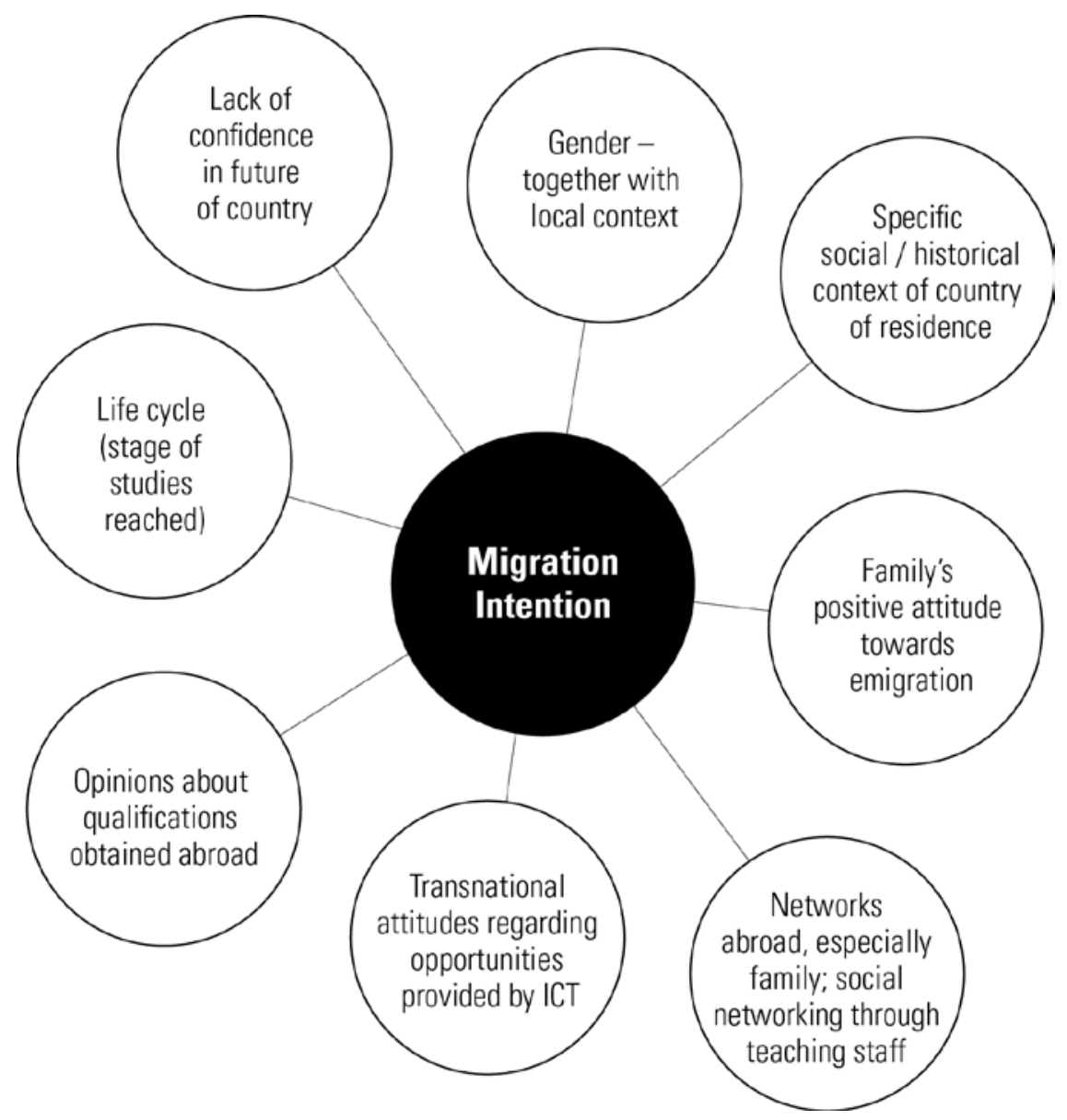

FIGURE 9.3 General explanatory framework of students' migration intentions. SOURCE: AUTHORS. 
Contrary to prevailing views - which tend to skew policy and media debate in developed countries-potential African migrants do not behave reactively when it comes to migration; they adopt a reflective, forward-looking attitude. This is demonstrated by a proper weighing of their interests in terms of educational, professional, and life experience. This was clear from the results of our questionnaires, and was corroborated by the interviews. A large majority of those interviewed (84 per cent) only had a temporary stay outside their country in mind. Their goal was to complete their education and, if possible, obtain a foreign qualification, or just gain new life experience. This matches the main reason mentioned by European students (Terrier, 2009), and also Tanzanian students (Prinz, 2006), and has been confirmed by other studies (Flahaux et al., 2011). The desire to pursue studies was a very frequently mentioned motivation in Niger and Senegal—indicated by over two-thirds of respondents. Similarly, it is only following an initial period of education at home that migration plans become more concrete.

Students who already hold a Master's degree are generally more inclined to consider leaving than those who find themselves at a less advanced stage. As mentioned earlier, it is not always possible for students to take their studies to a higher level at a home institution. However, there are agreements on the recognition of qualifications between some faculties and universities in member states of the Organisation for Economic Co-operation and Development (OECD) and among African universities, sometimes accompanied by the opportunity to obtain a grant. A number of the students who took part in this study also explained that their professors maintained or had established privileged contacts with universities overseas, which could help with their enrolment (Babo, 2009). Generally, the argument put forward by neoclassical migration theories (Piguet, 2013a), which contend that the desire to migrate arises mostly from economic dissatisfaction, has not been confirmed. The most disadvantaged university students are fully aware of the fact that they lack the necessary means to go abroad. They also understand that living conditions are more favourable abroad, but this does not make them more inclined to leave. Similarly, while unsatisfactory study and living conditions are certainly fertile ground for migration plans to take root, they are only rarely the main trigger. A lack of confidence in the home country's political future, on the other hand, has a clear influence on the intention to leave. On the whole, students' intention to emigrate does not appear to be an aim in itself or a sudden imperative. Instead, it is pondered as a stage of their career, with the objective of improving their education or leveraging their studies to improve their employment prospects. 
When it comes to the choice of destination countries, both the interviews and the questionnaire results show that students from Niger and Côte d'Ivoire more often consider migration within Africa (e.g. South Africa, Senegal, and Ghana) whereas Senegalese students look to destinations further afield. Generally speaking, only 11.3 per cent of students cited France (a former colonial power) as their preferred destination. France has been largely supplanted by Canada and the United States as the destination of choice. A wide range of countries was also mentioned, including some of the new hubs in the globalisation of knowledge such as South Africa, Saudi Arabia, and Japan (Figure 9.4) that offer attractive grants to African students, Saudi Arabia being especially keen to attract Muslim students.

Taking a closer look, student comments contain no shortage of arguments in favour of migration, mainly to the countries of the North. Aside from the more extensive educational opportunities, a large majority of respondents to the questionnaire felt that the quality of teaching was better outside their own countries, that a higher value was placed on competences, and also that those who have lived abroad receive more recognition once they return. Above all, most students (almost 80 per cent of respondents) consider that qualifications acquired abroad offer a distinct advantage both in terms of employment in the local labour market and for an academic career. This conviction is clearly confirmed by the relevant literature (Pinto, 2013; Prinz, 2006). The personal interviews also show that the marked interest in going to North America can be

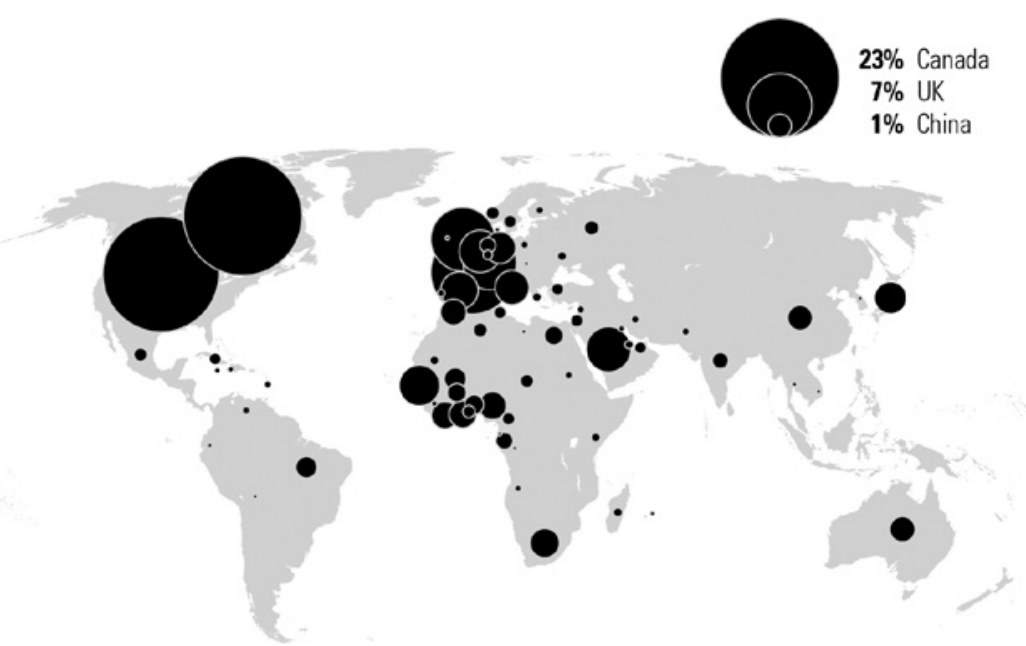

FIGURE 9.4 Destinations of choice for students from West Africa. SOURCE: AUTHORS. 
explained by a positive perception of an English-language education-English tends to be considered more as an opportunity than as a barrier-due to the simpler enrolment formalities and a less restrictive policy towards migrants than is considered to be the case in France and elsewhere in Europe.

Against this backdrop, investing in one's education abroad may be seen by potential migrants as a means of using the symbolic prestige of their course of study and the resultant degree to gain upward social mobility after completion of their studies (Waters, 2006). Thus, a class of local, foreign-educated elite develops in the country of origin. This is true for the public sector in particular, a throwback to the colonial period when native executives were educated in the Grandes Écoles of metropolitan France. In the private sector, these elites can contribute to the emergence of a transnational capitalist class (Findlay et al., 2012). Beyond considerations directly relating to the value of an academic degree, many students believe that the conditions for studying abroad, particularly in the countries of the North, are more satisfactory: better quality, delivery, and structure of teaching, and more advanced technologies. Students also feel that there are fewer 'disruptions', political interference, or 'deceit' within universities outside their home country. These considerations are certainly not without merit, given the shortage of resources and the lack of autonomy among the universities analysed. Following various structural adjustments, African higher education entered a critical phase in the 1980s. The problem of inadequate means, infrastructure, and human resources has grown even more acute now that African universities have to contend with burgeoning student populations resulting from demographic changes and rising school enrolment rates - albeit modest by international standards (Khelfaoui, 2009).

This starting position places African universities at a clear disadvantage in the globalised higher education market, which forms part of the global drive to recruit the best talents. Attendance at a university that is highly regarded in international rankings, along with transnational mobility, can confer a certain prestige to any student, irrespective of his or her country of residence. For students of West Africa, there is a further distinction, given the unequal progression of higher education institutions in developing countries compared to those in industrialised countries. This hiatus effectively encourages SouthNorth — or North-North—mobility, which is hardly favourable for the development of African universities, cut off as they are from other social spaces and from the economic world, and being subject to political interference. The Times Higher Education World University Rankings only included two African universities, both in South Africa, among the world's top 300 universities in 2012. According to Hocine Khelfaoui (2009), the reforms stemming from the 
Bologna process, which are essentially tailored to the needs of the European Union, only reinforce this unequal development. It is therefore hardly surprising that the reasons for the departure of staff and students-whether temporary or long term - are far from purely economic. It also explains why the rate of mobility abroad remains high, despite the admission restrictions put in place by countries of the North.

One of the main findings from our research is that education-driven migration offers considerable potential for the furthering of development aims. The evidence suggests that people are highly motivated to acquire the best possible education and training. This will continue to fuel transnational mobility in sub-Saharan Africa provided that it is not constrained by 'migration fears'. Obtaining a foreign qualification is certainly a strategy for acquiring symbolic capital. At the same time, it can also contribute to upward social mobility, which helps countries of origin by way of knowledge transfer. Our results show that, on the whole, migration intentions continue to be temporary as long as institutions remain stable and at least a minimum level of personal development is assured. This observation puts fears of a brain drain into perspective and makes the suggestion of a true circulation of competences more plausible.

These observations should prompt a shift in political focus away from purely migration-based considerations towards more general objectives of cooperation and development. They also raise the issue of African participation in the new European and global geography of education (Charlier and Croché, 2009). They argue in favour of greater coherence between policy sectors in both the North and South in order, for example, to tackle the paradox of restrictive entry policies for African students on the one hand and efforts by development agencies to foster access to higher education in the South on the other; a stance that Switzerland has started to adopt with its 'whole-of-government' approach to dialogue on migration and development. Promoting the voluntary mobility of African students and, more generally, working together to improve university courses is a positive way of reconciling migration and development objectives. The students whom we encountered were highly in favour of cooperation programmes to improve education in their countries of origin and offer opportunities to pursue additional studies abroad. Such programmes could potentially be included in mobility or migration partnerships. Despite their stated intentions, such partnerships have thus far failed to include this dimension to any 
meaningful extent, as immigration issues are always given priority over development issues in policy agendas.

\section{Conclusion}

A quick interpretation of our results could be that a dichotomy exists between African migrants who risk their lives to cross the Mediterranean and the students who agreed to take part in our survey. Apart from a potential desire to leave their continent, these two categories of people seem to have very little in common, as illustrated by the answer that students gave to the question of whether they would be prepared to migrate illegally: only 6 per cent of the students said that they would. The unpredictable actions of young, irregular migrants seem to be diametrically opposed to the reasoned career plans made by university students. While there certainly are differences between these two categories of potential migrants (e.g. different profiles, socioeconomic background, and resources at their disposal, and risk-taking capacity), the sociological reality of irregular migration may not be as clear-cut as humanitarian and security rhetoric would have us believe. These young Africans, who make sporadic appearances in the media, are motivated by a profound desire to do something with their lives, to seek opportunities and to make a name for themselves. This desire is at least as strong as their wish to flee conflicts or poverty. In this, the aspirations of irregular migrants do not seem so different from those of students. However, it is the students that are more likely to migrate to Europe (MAFE Project, 2013). Studies that have closely examined the lives of irregular migrants, rather than limiting themselves to a few quotes from survivors, lend credence to the idea that most of them, far from being naive or ill informed, also make highly conscious decisions within the realm of what is possible for them. They do so even if they lack sufficient means or transnational networks to implement their plans legally (Alpes, 2012; Bredeloup and Pliez, 2006; Bredeloup, 2013).

These observations also allow us to re-examine another dichotomy, this time engendered by the specialist literature that all too often considers student mobility as fundamentally distinct from other forms of migration and as only responding to the imperatives of education and careers. This productioncentred, 'non-family' vision is called into question by our results and by other recent research (Geddie, 2013; King and Raghuram, 2013), which underscores the importance of the role of the family, of transnational networks, and of partners in education-driven migration. It is therefore necessary to develop 
current theories further in order to better understand student mobility and certainly all forms of migration within the context of globalisation.

\section{References}

Alpes, M.J. (2012) 'Bushfalling at All Cost: The Economy of Migratory Knowledge in Anglophone Cameroon', African Diaspora, 5(1), pp. 90-115.

Armitage, C.J. and M. Conner (2001) 'Efficacy of the theory of planned behavior: A meta-analytic review', British Journal of Social Psychology, 40, pp. 471-499.

Babo, A. (2009) 'Quels partenariats scientifiques pour des universités africaines en crise? Le cas de la Côte d'Ivoire', in Droz, Y. and A. Mayor (eds.) Partenariats scientifiques avec l'Afrique: réflexions critiques de Suisse et d'ailleurs (Paris: Karthala), pp. 103-128.

Biraimah, K.L. (1987) 'Class, Gender and Life Chances: A Nigerian Case Study', Comparative Education Revue, 31(4), pp. 570-582.

Bredeloup, S. (2013) 'The Figure of the Adventurer as an African Migrant', Journal of African Cultural Studies, 25(2), pp. 170-182.

Bredeloup, S. and O. Pliez (2006) 'Migrations entre les deux rives du Sahara', Autrepart, 36, pp. 3-20.

Charlier, J.-E. and S. Croché (2009) 'Can the Bologna Process Make the Move Faster towards the Development of an International Space for Higher Education Where Africa Would Find Its Place?', Revue de l'enseignement supérieur en Afrique, 7(1-2), pp. 39-59.

Dalen, H.P. van, G. Groenewold and J.J. Schoorl (2005) 'Out of Africa: What Drives the Pressure to Emigrate?', Journal of Population Economics, 18(4), pp. 741-778.

De Jong, G.F. (2000) 'Expectations, Gender, and Norms in Migration Decision-Making', Population Studies, 54(3), pp. 307-319.

European Commission (2011) Youth on the move:Analyticalreport, Flash Eurobarometer Series 319b, http://ec.europa.eu/public_opinion/flash/fl_319b_en.pdf (accessed on 19 May 2014).

Fall, M. (2010) 'Migration des étudiants sénégalais', Hommes et Migrations, 1286-1287, pp. 222-233.

Fall, P.D. (2008) Les migrations africaines vers l'Europe: de l'appel de main-d'ouvre aux migrations clandestines vers les illes Canaries, text presented at the conference 'Migraciones internacionales e integración cultural en los espacios insulares: una perspectiva histórica', Universidad de La Laguna et Academia Canaria de la Historia, 2-4 June, Las Palmas de Gran Canaria.

Findlay, A.M., R. King, F.M. Smith, A. Geddes and R. Skeldon (2012) 'World Class? An Investigation of Globalisation, Difference and International Student Mobility', Transactions of the Institute of British Geographers, 37(1), pp.118-131. 
Flahaux, M.-L., C. Mezger and P. Sakho (2011) La migration circulaire des Sénégalais, CARIM-AS 2011/62, Robert Schuman Centre for Advanced Studies (San Domenico di Fiesole [FI]: European University Institute).

Geddie, K. (2013) 'The Transnational Ties That Bind: Relationship Considerations for Graduating International Science and Engineering Research Students', Population, Space and Place, 19(2), pp. 196-208.

Goudiaby, J.-A. (2009) 'Le Sénégal dans son appropriation de la Réforme LMD: déclinaison locale d'une réforme "globale"', Revue de l'enseignement supérieur en Afrique, 7(1-2), pp. 79-93.

Harbinson, S. (1981) 'Family Structure and Family Strategy in Migration Decision Making, in De Jong, G.F and R.W. Gardner (eds.), Migration Decision Making: Multidisciplinary Approaches to Microlevel Studies in Developed and Developing Countries (New York: Pergamon Press), pp. 225-25l.

Khelfaoui, H. (2009) 'Le Processus de Bologne en Afrique: globalisation ou retour à la "situation coloniale"?', Revue de l'enseignement supérieur en Afrique, 7(1-2), pp. 1-20.

King, R. and P. Raghuram (2013) 'International Student Migration: Mapping the Field and New Research Agendas', Population, Space and Place, 19(2), pp. 127-137.

Kunzler, D. (2008) L'éducation pour quelques-uns?: Enseignement et mobilité sociale en Afrique au temps de la privatisation: le cas du Bénin (Paris: Editions L'Harmattan).

Lebeau, Y. (1997) 'The daughters of evil! Images de l'étudiante sur les campus nigérians', Politique africaine, 65, pp. 21-34.

Lu, M. (1999) 'Do People Move When They Say They Will? Inconsistencies in Individual Migration Behavior', Population and Environment, 20(5), pp. 467-488.

MAFE Project (2013) 'Factors of Migration between Africa and Europe: Assessing the Role of Education, Family and Policy', MAFE Project Briefing Paper, No. 3 (Paris: Institut national d'études démographiques).

Mounkaila, H., B. Amadou and F. Boyer (2009) 'Le Niger, espace d'émigration et de transit vers le sud et le nord du Sahara: rôle et comportements des acteurs, recompositions spatiales et transformations socio-économiques', Document de synthèse des projets du programme FSP 2003-74: migrations internationales, recompositions territoriales et développement (Paris: Institut de recherche pour le développement), pp. 109-120.

Ndione, B. (2007) 'Contexte local et migration: l'exemple des dynamiques migratoires internationales de quartiers dans la ville sénégalaise de Kaolack', Revue européenne de démographie, 25(3), pp. 325-354.

Palloni, A., et al. (2001) 'Social Capital and International Migration: A Test Using Information on Family Networks', American Journal of Sociology, 106(5), pp. 1262-1298.

Piguet, E. (2013a) 'Les théories des migrations: synthèse de la prise de décision individuelle', Revue européenne des migrations internationales, 29(3), pp. 141-161. 
(2013b) The Move to Move: What Motivates West African University Students to Consider Leaving Their Countries, working paper (Geneva: Swiss Network for International Studies), http://www.snis.ch/system/files/movetomove_0.pdf (accessed on 3 April 2014).

Pinto, C. (2013) Mobilité sociale et mobilité internationale d'étudiants étrangers: trajectoires de jeunes professionnels chiliens et colombiens à Paris, New York et Boston, doctoral thesis, Université Paris-Est.

Prinz, V. (2006) Imagine Migration: The Migration Process and Its Destination Europe in the Eyes of Tanzanian Students (Vienna: Südwind-Verlag).

Tabapssi, T. (2010) La migration hautement qualifiée au Niger, CARIM-AS 2010/16, Robert Schuman Centre for Advanced Studies (San Domenico di Fiesole [FI]: European University Institute).

Terrier, E. (2009) 'Les migrations internationales pour études: facteurs de mobilité et inégalités Nord-Sud', L'Information géographique, 73(4), pp. 69-75.

van Dalen, H.P., G. Groenewold and J.J. Schoorl (2005) 'Out of Africa: What Drives the Pressure to Emigrate?', Journal of Population Economy, 18, pp. 741-778.

Waters, J.L. (2006) 'Geographies of Cultural Capital: Education, International Migration and Family Strategies between Hong Kong and Canada', Transactions of the Institute of British Geographers, 31(2), pp. 179-192. 